\title{
La delación premiada en España: instrumentos para el fomento de la colaboración con la justicia
}

\author{
Rewarded delation in Spain: instruments for the \\ promotion of collaboration with justice
}

Juan Carlos Ortiz ${ }^{1}$

Professor da Universidad de Castilla-La Mancha (ESP)

JuanCarlos.Ortiz@uclm.es

http://orcid.org/0000-0001-6092-6137

\begin{abstract}
Resumen: Junto con los clásicos debates jurídicos referidos a la atribución o no al Ministerio Fiscal de la fase de investigación, junto con la introducción en nuestro sistema procesal del principio de oportunidad penal, cada vez cobra mayor atención en España la conveniencia de articular medidas legales que incentiven la colaboración con la Justicia, y en especial, las confesiones y delaciones de criminales arrepentidos, como instrumentos que favorecerían la obtención de valiosa información y fuentes de prueba, sobre todo en lo que se refiere a la delincuencia económica. El presente estudio expone las distintas figuras jurídicas utilizadas actualmente como incentivos para premiar la delación de colaboradores, testigos y acusados, y examina su evolución de cara a su futura incorporación a la normativa procesal española.
\end{abstract}

Palabras clave: Derecho Premial; Delación; Corrupción; Justicia Penal; España.

ABSTRACT: There are two classical debates in Spain, referred to the attribution or not of the investigating phase to the Prosecution Office, and the introduction of the discretionary power (principle of opportunity) in our Justice system. Besides them, there is a new legal debate about the convenience of articulating legal measures that encourage the collaboration with the justice, and especially, the confessions and denunciations of criminal repentants, as

1 Professor titular da Universidad de Castilla-La Mancha (UCLM). Doutor em Direito pela UCLM (2005). 
instruments that would favor the obtaining of valuable information and sources of evidence, especially referred to white-collar crime. This study exposes the different legal figures used currently in Spain as incentives to reward the delation of collaborators, witnesses and defendants, and examines its evolution with a view to their future incorporation into the Spanish procedural law.

KeYwords: Brivery; Fraud; Delation; Rewards; Criminal Justice; Spain.

\section{CORRUPCIÓN Y MEDIOS EXTRAORDINARIOS DE INVESTIGACIÓN}

Los múltiples casos de corrupción que en los últimos años han aflorado en España (blanqueo de capitales, evasión fiscal, defraudación a la Hacienda Pública y a la Seguridad Social, etc.) y en los que se acusa a políticos, empresarios, sindicalistas, etc., han conducido en la práctica a que la ciudadanía perciba la corrupción y el fraude como la segunda preocupación de los españoles, solo por detrás del desempleo, según los distintos barómetros del Centro de Investigaciones Sociológicas (CIS) correspondientes a los años 2013 a $2016^{2}$. No en vano, siempre se ha advertido que la delincuencia económica desmoraliza al consumidor ${ }^{3}$, pues el incremento de las infracciones penales en el desarrollo de las relaciones económicas internacionales perjudican no sólo a los socios, accionistas, asalariados, comerciantes de la competencia, clientes, o acreedores, sino también a la comunidad en su conjunto e incluso al Estado al que impone pesadas cargas financieras y al que inflige pérdidas considerables de ingresos, gravando, por consiguiente, a la economía nacional e internacional ${ }^{4}$.

2 Los Estudios del Centro de Investigaciones Sociológicas están disponibles en la página web http://www.cis.es/cis/opencms/ES/index.html.

3 RUIZ VADILLO, E., "La reforma penal y la delincuencia económica. Especial referencia a la protección del consumidor”, Eguzkilore, núm. Extra 1999, p. 51.

4 Así se ha reconocido expresamente, por ejemplo, en las Recomendaciones del Consejo de Europa sobre criminalidad económica (Recomendación núm. R (81) 12, del Comité de Ministros, de 25 de junio de 1981 sobre la criminalidad en materia económica) y sobre el papel del Derecho Penal 
Ante situaciones excepcionales, los Estados suelen tender a aprobar medidas excepcionales también en el ámbito de la investigación criminal. Por ello, ante la percepción de que la Justicia española necesita nuevos instrumentos que mejoren la eficacia en la persecución de la llamada "delincuencia de cuello blanco", se ha vuelto a retomar el debate jurídico respecto a la conveniencia o no de potenciar fórmulas premiales y de justicia negociada, que ya son aplicadas en otros países como herramientas muy efectivas para destapar, investigar y castigar todas esas conductas relacionadas con la corrupción pública y la delincuencia económica empresarial, en las que el perjudicado final es la economía de un país, y por lo tanto, el ciudadano como último eslabón de la cadena sobre el que recaen las consecuencias sociales y patrimoniales más dolorosas a la hora de evitar la quiebra estatal.

En efecto, una privilegiada fuente de información para destapar ciertas tramas delictivas relacionadas con la delincuencia económica y la corrupción y conseguir eficaces pruebas de cargo para su condena suelen ser los propios miembros de dicha trama, los empleados que conocen las irregularidades internas y quieren informar (máxime cuando son despedidos), o los empresarios y demás sujetos sobornados que dejan de recibir un trato privilegiado y deciden "tirar de la manta”. De ahí la trascendencia que puede llegar a tener para las autoridades la obtención de información esencial a través de la colaboración de chivatos y soplones -delatores en general. Y quizá por ello, resulta entendible que los países hayan procedido a incluir diversas medidas legales para fomentar y premiar las delaciones y las autodenuncias de criminales arrepentidos, entre las que sobresalen, la protección de la identidad del informante frente a posibles represalias, la mitigación de la pena (atenuantes por colaboración activa) e incluso la exención de responsabilidad penal, o diversos modelos de inmunidad procesal (archivo de la acción penal en su contra o suspensión de la misma sujeta a diversas condiciones) para quien se presta a colaborar con las autoridades en la obtención de datos y fuentes de prueba de los delitos cometidos dentro de su organización y a prestar una cooperación sustancial en la investigación de los mismos. 


\section{JUSTICIA Y DELACIÓN}

A pesar de las ventajas que se derivarían de acceder a esa sustancial información a cambio de ciertos incentivos o premios, lo cierto es que la delación nunca ha sido bien vista en nuestro país y la imagen del delator, que siempre ha sido asociada con las características más ruines y mezquinas del ser humano, no ha sido bien recibida ni por la Sociedad ni por la Justicia ${ }^{5}$. Socialmente, vemos como el Diccionario de la Real Academia Española de la Lengua identifica la voz «delator» como la persona que denuncia o acusa a otros, pero con un matiz especial: "en secreto y cautelosamente”, y en el lenguaje común se utilizan sinónimos como "soplón”, “traidor", “chivato" o "judas”. Precisamente este último adjetivo ilustra el porqué de esta denostada imagen del delator: el origen de la delación se remonta a la propia existencia del ser humano desde el propio pecado original, pues Adán delató a Eva, y ésta a la serpiente ${ }^{6}$. Y resulta que el delator premiado más famoso de la historia de la humanidad es quizás Judas Iscariote, quien recibió de los sacerdotes treinta monedas de plata a cambio de traicionar a su líder

En el ámbito jurídico, la Justicia tampoco ha valorado positivamente el empleo de la delación como herramienta legal para la obtención de información. De una parte, quizás debido a la especial influencia de lo religioso en el sistema penal inquisitorial que caracterizó nuestro sistema legal de siglos pasados, en donde esa correlación casi gráfica entre la delación y el pecado original y con la traición a Jesucristo hizo que la delación nunca fue regulada como un modo ordinario de facilitar o recibir información útil para las causas judiciales, sino como una herramienta extraordinaria y excepcional, tolerable en casos extremos, en los que sus reprochables atributos - el secretismo y el anonimato son sus principales características - se veían justificados sólo en casos extremos o de circunstancias especiales. Y de otra parte, quizás también porque la delación siempre se ha correlacionado con los Estados totalitarios y sus sistemas de vigilancia universal e intimidatoria ideados para obte-

\footnotetext{
5 Al respecto, vid. ORTIZ PRADILLO, J. C., "El difícil encaje del delator en el proceso penal” en el Diario La Ley, núm. 5860, de 12 de junio de 2015, pp. 1-10.

6 Génesis, 3-12.

7 Mateo 26:14-16; Lucas 22:1.
} 
ner información subrepticiamente por parte de los "buenos y patriotas ciudadanos" prestos a colaborar con el régimen, pues el uso y fomento de informantes y delatores fue una característica común a la Alemania nazi, la Italia fascista, la Rusia estalinista, o la España franquista, por citar algunos ejemplos.

\section{INCENTIVOS Y MEDIDAS PREMIALES PARA EL COLABORADOR CON LA JUSTICIA}

A pesar de estas premisas iusfilosóficas contrarias al uso de la delación como instrumento de obtención de información, y a falta de una reforma del sistema procesal penal español que incorpore distintas modalidades de retirada o suspensión de la acusación por colaboración con la Justicia, basada en motivos de oportunidad (salvo excepciones puntuales en algunos delitos leves ya utilizables), el ordenamiento jurídico español cuenta con diversos instrumentos legales a los que la Jurisprudencia ha acudido últimamente a la hora de incentivar al máximo esa colaboración con la Justicia, mediante la aportación de información esencial para el proceso penal, por parte de los ciudadanos, testigos, trabajadores, coimputados, e incluso reos arrepentidos.

A continuación se expondrán los principales instrumentos legales previstos en el ordenamiento jurídico para fomentar la colaboración con la Justicia.

\subsection{LA ADMISIBILIDAD DE LAS DENUNCIAS ANÓNIMAS}

Como quiera que la información procedente de las denuncias anónimas resulta en ocasiones trascendental para la identificación de los autores de una conducta criminal o la averiguación de sus fechorías, y aunque legalmente la Ley de Enjuiciamiento Criminal española exija identificar al sujeto denunciante, lo cierto es que oficiosamente - en la práctica - la obtención de información de fuentes anónimas o confidenciales siempre ha sido un recurso admitido y legitimado por las autoridades encargadas de la investigación criminal.

En este sentido, la historia de la delación anónima en España se ha calificado como "el propio ritmo de las mareas, con sus subidas 
y sus retrocesos" $"$. Ha habido episodios históricos en los que se prohibía expresamente la delación anónima, como por ejemplo en algunas Constituciones Sinodales de los siglos XVI-XVII, que prohibían recibir denuncias no firmadas por ningún autor, estableciéndose la regla de que "El Fiscal no reciba denunciación que no venga firmada de quien se la diere (...) por evitar la malicia de los que procuran molestar a las personas con quien tienen algún odio o enemistad, dando denunciaciones a nuestro Fiscal de delitos algunas veces falsos ${ }^{9}$ ". Y también en la Novísima recopilación de las leyes de España ${ }^{10}$, en el Título XXXIII del Libro XII (de las delaciones y acusaciones) se prohibía expresamente a los Fiscales y Promotores de la Justicia acusar y denunciar sin dar delator, salvo en los casos que sean notorios, y se exigía que "el tal delator diga por ante Escribano público la delación, y de otra manera no se reciban las dichas acusaciones y demandas y denunciaciones”.

Pero es igualmente cierto que las delaciones anónimas han sido toleradas, e incluso legalmente promovidas en nuestro sistema legal. Así, en el Título XI de la Novísima Recopilación (de los tumultos, asonadas y conmociones populares) se advertía que los autores "serán aprehendidos por los Jueces y Justicias del reyno, poniéndose en testimonio separado el nombre del delator, que se mantendrá siempre en secreto con toda fidelidad”. En el Título XXV (de las injurias, denuestos y palabras obscenas) se establecía igualmente que quedaban prohibidos los pasquines y papeles sediciosos e injuriosos a personas públicas, y en caso de averiguación por la Sala, Corregidor y Tenientes cualquier contravención que hubiere, "se mantendría en secreto el nombre del

8 RUBIO EIRE, J. V., "La posible inviabilidad de una denuncia anónima o fundada en fuentes no verificables como elemento precursor de una instrucción penal". Documento online disponible en la página web:http://www. elderecho.com/penal/inviabilidad-verificables-elemento-precursor-instruccion_11_560680001.html. Fecha de consulta: 12 de mayo de 2015.

9 DE MOSCOSO Y SANDOVAL, B., Constituciones Sinodales del obispado de Jaén. Sínodo diocesana que se celebró en la ciudad de Jaén en 1624. Segunda impresión, Jaén, 1787, p. 146.

10 Recopilación ordenada por Felipe II en el año 1567. Así se cita la recopilación mandada formar por Carlos IV en 1805, en la que se incorporan las pragmáticas, cédulas, decretos, órdenes y resoluciones reales, y otras providencias expedidas hasta 1804, Volumen 1. 
delator en testimonio separado". Y también la Pragmática de Carlos III de 17 de abril de 1774 establecía que los cómplices en bullicios o conmociones populares que dieren pronta cuenta a las Justicias "quedarán sus nombres en testimonio reservado".

En el proceso penal español vigente, la solución a la hora de decidir qué efectos procesales otorgar a la presentación de una denuncia anónima se anticipó en la Instrucción de la Fiscalía General del Estado $3 / 1993$, de 16 de marzo, en la que se admitía que "una denuncia carente de aptitud como tal presupuesto procesal desencadenante puede servir, en su contenido material, como medio transmisor de la noticia de unos hechos que justifiquen la incoación ex officio de la primera fase del proceso (...). No cabe duda que, con independencia de la idoneidad formal de la denuncia como tal, ésta podrá ser reputada instrumento transmisor válido de una noticia criminal", aunque se concluía afirmando que "la ponderación de la conveniencia de iniciar una fase de investigación preparatoria con origen en una denuncia anónima habrá de calibrar, fundamentalmente, el alcance del hecho denunciado, su intensidad ofensiva para un determinado bien jurídico, la proporcionalidad y conveniencia de una investigación por hechos cuyo relator prefiere ampararse en el ocultismo y, en fin, la legitimidad con la que se pretenden respaldar las imputaciones delictivas innominadas". Esta tesis ha sido consolidada jurisprudencialmente, cuyo mejor ejemplo lo ilustra la Sentencia del Tribunal Supremo (STS) 318/2013, de 11 de abril, en la que tras recopilar la principal jurisprudencia favorable a legitimar la comprobación policial o judicial de lo manifestado a través de una denuncia anónima, se asienta la siguiente doctrina: "Nuestro sistema no conoce, por tanto, un mecanismo jurídico que habilite formalmente la denuncia anónima como vehículo de incoación del proceso penal, pero sí permite, reforzadas todas las cautelas jurisdiccionales, convertir ese documento en la fuente de conocimiento que, conforme al art. 308 de la LECrim, hace posible el inicio de la fase de investigación (...). Un sistema que rindiera culto a la delación y que asociara cualquier denuncia anónima a la obligación de incoar un proceso penal, estaría alentado la negativa erosión, no sólo de los valores de la convivencia, sino el círculo de los derechos fundamentales de cualquier ciudadano frente a la capacidad de los poderes públicos para investigarle. Pero nada de ello 
impide que esa información, una vez valorada su integridad y analizada de forma reforzada su congruencia argumental y la verosimilitud de los datos que se suministran, pueda hacer surgir en el Juez, el Fiscal o en las Fuerzas y Cuerpos de Seguridad del Estado, el deber de investigar aquellos hechos con apariencia delictiva de los que tengan conocimiento por razón de su cargo".

\subsection{LA PROTECCIÓN DE LA IDENTIDAD DE CONFIDENTES Y TESTIGOS}

La utilización de confidentes policiales en España fue fuertemente criticada en su momento por Velasco Núñez, entre otros motivos, porque "la colaboración de los confidentes suele quedar condicionada a un beneficio personal, lo que no deja de ser un chantaje a los organismos oficiales encargados de perseguir el delito, y porque sirve para crear contrapoderes marginales y corrupciones funcionariales, por desarrollarse fuera del cauce de la ley, y cuanto menos, lleva a fines netamente intrapoliciales (v. gr., asegurarse futuras fuentes de información) que no siempre acaban siendo ventajosas y que muchas veces generan en el funcionario deudas y chantajes difíciles de acallar (...), y lo que es peor de todo, puede llevar a quien crea en el confidente a creer y originar una investigación que no es sino una infamia, para quien no tiene delito, pues es de presumir que quien oculta su rostro para acusar también será capaz de ocultar la verdad en lo que acusa"11.

A diferencia del denunciante anónimo, el confidente policial es un delator cuya identidad es conocida por las autoridades policiales y que da cuenta de diversas informaciones que posee, pese a lo cual no es llamado para declarar judicialmente ni a comparecer como testigo sobre tales informaciones en el correspondiente proceso, pues los tribunales han admitido que la policía no tiene que revelar la fuente inicial de investigación cuando se trata de un confidente ${ }^{12}$. Para la jurisprudencia, nada tiene de anómalo ni de constitucionalmente ilícito que la policía utilice fuentes confidenciales para recabar información que abran el camino a su actividad constitucionalmente establecida de averiguación del

11 VELASCO NÚÑEZ, E., “El confidente”, La Ley, 1993, pp. 823-830.

12 Vid., por todas, las SSTS 834/2009, de 29 de julio y 654/2013, de 26 de junio. 
delito y aseguramiento del delincuente ${ }^{13}$, pues el valor de un testimonio anónimo se limita única y exclusivamente a dirigir u orientar una investigación policial, sin que los policías que se han servido de confidentes queden obligados a revelar cuáles son sus fuentes de información, y si a partir de tales pesquisas iniciales aparecieran datos incriminatorios se podría dar lugar a la apertura de una encuesta judicial ${ }^{14}$.

Ahora bien, la jurisprudencia ha advertido expresamente dos líneas rojas a la hora de servirse de delatores confidenciales para la investigación criminal y la posterior sentencia condenatoria de los autores. De una parte, dichas confidencias anónimas en modo alguno pueden ser utilizadas como prueba de cargo, ni siquiera a través de la declaración de los testigos de referencia ${ }^{15}$. Y de otra, tampoco puede servir como indicio directo y único para adoptar medidas restrictivas de derechos fundamentales ${ }^{16}$, salvo supuestos excepcionalísimos de estado de necesidad (peligro inminente y grave para la vida de una persona secuestrada, por ejemplo).

Con respecto a la protección de los testigos en el proceso penal, y más allá de la infrecuente aplicación del art. 464 CP para el supuesto

13 Vid. SSTS de 19 de febrero y de 4 de abril de 2003.

14 STS de 1 de diciembre de 2006. Véase el apartado 13.3.2 (Informaciones anónimas) de la Circular 1/2013, según el cual "La policía no tiene que revelar la fuente inicial de investigación cuando se trata de un confidente (SSTS núm. 121/2010, de 12 de febrero, 834/2009, de 29 de julio) pues ello «podría provocar venganzas y represalias contra los terceros informantes, a la vez que privaría a la policía de un medio de investigación legítimo y valioso, al desalentar cualquier propósito colaborador de la ciudadanía en la lucha contra la delincuencia» (STS núm. 751/2006, de 7 de julio)”.

15 En su STC 155/2002, de 22 de julio, el Tribunal Constitucional declaró expresamente que "de un lado, incorporar al proceso declaraciones testificales a través de testimonios de referencia implica la elusión de la garantía constitucional de inmediación de la prueba al impedir que el Juez que ha de dictar Sentencia presencie la declaración del testigo directo, privándole de la percepción y captación directa de elementos que pueden ser relevantes en orden a la valoración de su credibilidad. De otro, supone soslayar el derecho que asiste al acusado de interrogar al testigo directo y someter a contradicción su testimonio, que integra el derecho al procesa con todas las garantías del art 24.2 CE y que se encuentra reconocido expresamente en el párrafo 3 del art 6 del Convenio europeo de derechos humanos como una garantía específica del derecho al proceso equitativo del art 6.1 del mismo".

16 Vid, por todas, las SSTS de 26 de septiembre de 1997, 8 de marzo y 12 de abril de 2012. 
de que se intentase influir al denunciante, testigo, parte o imputado, para que modifique su declaración procesal, resulta constatable como uno de los principales obstáculos para promover la colaboración ciudadana se ha situado en la insuficiencia de las medidas previstas en la Ley Orgánica 19/1994, de 23 de diciembre, de Protección de Testigos, a la hora de establecer mecanismos de seguridad para quienes comparecen a juicio con el objeto de colaborar con la Administración de Justicia frente a eventuales peligros que puedan proceder de la persona o grupo para quienes ese testimonio pueda ser utilizado como prueba de cargo de un ilícito penal ${ }^{17}$. El problema se resume claramente en la STS 525/2012, de 19 de junio, de la siguiente manera: "La práctica de las declaraciones de testigos protegidos en el plenario suscita algunos problemas, derivados de la necesidad de compatibilizar los derechos del acusado, especialmente a conocer las pruebas de cargo y a intervenir en ellas en igualdad de armas con la acusación bajo la vigencia del principio de contradicción, con los derechos del testigo a la seguridad, que es necesario proteger para garantizar la indemnidad de aquel y desde otra perspectiva, para facilitar la colaboración del ciudadano con la Justicia. Y ello no solo en relación con su identificación, sino también en cuanto a la forma en que la declaración se lleva a cabo".

Además, y debido a la delgada línea roja que separa entre testimonios ocultos y testimonios anónimos según la doctrina vertida por el $\mathrm{TEDH}^{18}$, la aplicación al delator de estas medidas legales de protección de testigos que prevé la legislación española puede no ser un incentivo suficiente para obtener dicha colaboración, debido a un límite muy importante: la normativa española no establece con carácter absoluto un completo anonimato del delator cuando la defensa requiera motivadamente el conocimiento de la identidad de aquel para asegurar un

17 Sobre la aplicación de las medidas de protección de testigos al colaborador con la Justicia, vid. SÁNCHEZ GARCÍA DE PAZ, I., "El coimputado que colabora con la Justicia penal (con atención a las Reformas introducidas en la Regulación españolas por las leyes 7 y 15/2003)”, Revista electrónica de Ciencias penales, núm. 7, 2005 (versión online disponible en: http://criminet.ugr.es/recpc/) y CUBILLO LÓPEZ, I. J., La protección de testigos en el proceso penal, ed. Thomson Reuters, Madrid, 2009, p. 35 y ss.

18 Un importante resumen de la doctrina del TEDH se recoge en la STC 75/2013, de 8 de abril de 2013. 
correcto ejercicio del derecho de defensa, tal y como ha recordado repetidamente el TEDH, lo cual no parece que proporcione la protección más adecuada ${ }^{19}$ en un ámbito especialmente complejo y delicado que, cual es apodíctico, debería ser objeto de una regulación general a nivel de la Unión Europea, donde se aborde la problemática de la revelación de la identidad del testigo o testigos.

No obstante, también en este aspecto podemos apreciar una importante evolución jurisprudencial en España, con el fin de facilitar la validez de las delaciones vertidas por testigos anónimos, dirigida a suavizar el mandato contenido en el apartado $3^{\circ}$ del art. 4 de la L.O. 19/1994, según el cual ante una solicitud motivada de las partes sobre el conocimiento de la identidad de los testigos o peritos propuestos, cuya declaración o informe sea estimado pertinente, dice la norma que el Juez "deberá facilitar el nombre y los apellidos de los testigos y peritos, respetando las restantes garantías reconocidas a los mismos en esta Ley". El Tribunal Supremo ha declarado que el mandato contenido en el apartado $3^{\circ}$ del art. 4 de la referida L.O. 19/1994 no puede interpretarse en absoluta desconexión con el número 1, que permite a la Sala mantener las medidas protectoras acordadas durante la instrucción, por lo que el deber de revelar el nombre y apellidos de los testigos no es, en modo alguno, de carácter absoluto ${ }^{20}$, sino que el órgano judicial deberá valorar la suficiencia y razonabilidad de la petición motivada de la defensa de revelar la identidad del testigo protegido. Según el Tribunal Supremo, "el Tribunal debe realizar una ponderación entre los intereses contrapuestos (seguridad del testigo-derecho de defensa del acusado) que exige valorar la razonabilidad y suficiencia de la motivación expuesta por la solicitud de desvelar la identidad del testigo protegido, atendiendo por un lado a las razones alegadas para sostener que en el caso concreto el anonimato afecta negativamente al derecho de defensa, y por otro a la gravedad del riesgo apreciable para el testigo y su entorno, en atención a las circuns-

19 ARIAS RODRÍGUEZ, J. M., "Algunas reflexiones sobre la política anticorrupción en la Unión Europea”, Diario La Ley, núm. 7989, de 21 de diciembre de 2012.

20 Vid. STS 395/2009, de 16 de abril, y la jurisprudencia contenida en la misma: SSTS 322/2008, 30 de mayo; 1047/2006, 9 de octubre; 98/2002, 28 de enero; 1027/2002, 3 de junio y $961 / 2006,25$ de septiembre. 
tancias del caso enjuiciado" de modo que si bien "el desconocimiento de la identidad del testigo puede impedir a la defensa conocer, y en consecuencia expresar al Tribunal, las razones concretas por las que el testigo anónimo puede ser parcial o carecer de credibilidad", advierte que "en la práctica ha de tenerse en cuenta que el conocimiento del contenido de la declaración realizada durante la instrucción permite ordinariamente al afectado inferir ciertos datos sobre la personalidad del testigo, que permitan a la defensa fundamentar racionalmente su solicitud ${ }^{21}$ ".

Como vemos, por obra de la jurisprudencia del Tribunal Supremo se ha ampliado la preservación del anonimato también durante la fase de enjuiciamiento (lo cual supone un interesante incentivo para que el delator se decida a colaborar) y se ha declarado que "para que puedan operar como prueba eficaz de cargo los testimonios anónimos, aparte de que esté justificada la necesidad del anonimato, es preciso que tal situación aparezca compensada por un interrogatorio de la defensa que permita apreciar la fiabilidad y veracidad del testimonio, y señalándose también el matiz importante de que éste nunca podría servir como única prueba de cargo o como prueba incriminatoria decisiva para fundamentar la condena ${ }^{22}$ ".

\subsection{LAS RECOMPENSAS AL DELATOR}

El establecimiento de honores, premios y recompensas, incluso de carácter económico, a quien denuncia una conducta prohibida o comunica a las autoridades la comisión de algún delito, es también una fundamental herramienta de obtención de información. Aunque es habitual que la doctrina contemporánea, a la hora de referirse a los principales exponentes de instrumentos legales para la promoción jurídica de la delación a través de recompensas económicas, señale los

21 STS núm. 384/2016, de 5 de mayo.

22 STS 378/2009, de 27 de marzo. En concreto, el Tribunal Supremo ha señalado que el interrogatorio del testigo anónimo, a lo sumo habría de operar como dato secundario meramente corroborador de la prueba principal de cargo. Sin perjuicio, claro está, de que la condena pueda apoyarse en otras pruebas incriminatorias que contengan entidad suficiente para enervar el derecho a la presunción de inocencia (STS 828/2005, de 27 de junio). 
EE.UU., Reino Unido o Australia, en donde existen programas de incentivos (Bounty Programs) a través de los cuales se otorgan recompensas económicas al delator en función de las cantidades que el Estado llegue a recuperar al descubrir la trama delictiva, hay que advertir que tales recompensas económicas ya existían en el Derecho Romano.

Frente a la expresión "Roma no paga traidores ${ }^{23}$ ", lo cierto es que Roma sí incentivaba la delación, no sólo con medidas de protección, sino también a través de recompensas económicas. Un ejemplo literario lo encontramos en La conjuración de Catilina de SALUSTIO, quien nos cuenta que "por decreto del Senado, si alguien hubiera señalado algo sobre la conjuración, que se había hecho contra la República, decretaron como premio la libertad y cien mil sestercios para un esclavo, y la impunidad de este hecho y doscientos mil sestercios para un hombre libre ${ }^{24}$ ".

Ejemplos legales de premios y recompensas ideados para fomentar las denuncias durante la etapa romana los encontramos en la Lex Acilia repetundarum (año 123 a. C.), norma en la que se preveía que, si la acusación prosperaba, la recompensa podía consistir en la concesión de alguna dignidad, como por ejemplo, un ascenso en el rango senatorial; la consecución de un cargo importante ${ }^{25}$; e incluso la obtención de la ciudadanía romana ${ }^{26}$; la exención del servicio militar (vacatio publici muneris et militiae ${ }^{27}$ ). En la lex Papia Poppaea (año 9 a. C.), también se establecían recompensas económicas que podían alcanzar hasta

23 Frase atribuida a Quinto Servilio Cepión y que sucedió en la península ibérica, con motivo del asesinato del general lusitano Viriato (año 139 a. C.) a manos de sus propios soldados sobornados por Roma con la promesa de grandes riquezas y tierras, quienes cuando fueron a reclamar tales recompensas a Quinto Servilio Cepión, éste se las negó y ordenó asesinarles al grito de "Roma traditoribus non praemiat". capítulo XXX-6

25 CASTRO CAMERO, R., El crimen maiestatis a la luz del senatus consultum de Cn. Pisone Patre, ed. Universidad de Sevilla, Sevilla, 2001, p. 158.

26 Recompensa expresamente establecida en las líneas 76-83 de la Ley, y mencionada por Cicerón en su discurso Pro Balbo, aptdos. 22-24.

27 GUERRERO, M., "El praemium civitatis en la lex Acilia repetundarum: ¿incentivo para reprimir el abuso de poder?", Rivista Internazionale di Science Giuridiche e Tradizione Romana, nr. 12, 2014. Versión online disponible en la página web: http://www.dirittoestoria.it/12/tradizione-romana/GuerreroPraemium-civitatis-lex-Acilia.htm. 
la mitad de determinados bienes (caducum) para quienes pusieran en conocimiento de los agentes del fisco la existencia de bienes vacantes (bona vacantia) sin titular al no haber sido aceptados por ninguno de los herederos $^{28}$. Y en la Lex Iulia Maiestatis (año 8 a. C), se establecía como premio un cuarto de la multa impuesta al condenado o con un cuarto de sus bienes confiscados ${ }^{29}$.

En diversos países de América Latina se han aprobado diversas leyes que prevén recompensas económicas para quien facilite información en materia penal. Por citar algunos ejemplos, así se establece en la Ley Federal mexicana contra la delincuencia organizada de 7 de noviembre de 1996; en las leyes argentinas $n^{0} 25.765$ de 2003 y no 26.538 de 2009 que regulan el Fondo Permanente de Recompensas; en Colombia cuentan con la Ley 282 del 6 de junio de 1996 - “Ley Antisecuestro”-y la Ley 418 de 1997; en Nicaragua, el art. 50 del Decreto 70-2010, de 12 de Noviembre del 2010, por el que se aprueba el Reglamento de la Ley de Prevención, Investigación y Persecución del Crimen Organizado y de la Administración de los Bienes Incautados, Decomisados y Abandonados; en Honduras, el Decreto $\mathrm{n}^{\mathbf{0}} 21-2014$, de 13 de junio de 2014, regula la Ley de Recompensas por la información de aquellas personas que, sin haber intervenido en el delito, brinden datos útiles para lograr la aprehensión de quienes hubiesen tomado parte en la ejecución de los delitos; y en Perú, destacan la Ley de exclusión o reducción de pena, denuncias y recompensas en los casos de delito e infracción tributaria (Decreto Legislativo núm. 815, de 20 de abril de 1996), la Ley 29.542 de 2010 sobre protección al denunciante en el ámbito administrativo y de colaboración eficaz en el ámbito penal, y el Decreto Legislativo no 1180 de 27 de julio de 2015 sobre el Beneficio de Recompensa para promover y lograr la captura de Miembros de organizaciones criminales, organizaciones terroristas y responsables de delitos de alta lesividad.

En España, por el contario, no parece existir un argumentado debate a favor de la introducción de este tipo de incentivos económicos

28 GARCÍA CAMIÑAS, J., Delator, una aproximación al estudio del delator en las fuentes romanas, Santiago de Compostela, 1983. Vid. también Ídem, "Deferre ad aerarium", AFDUDC, núm. 10, 2006, pp. 431-451.

29 CATTAN ATALA, A., LOYOLA NOVOA, H., "Los delatores", Revista Chilena de Historia del Derecho, núm. 14 (1991), pág. 36. 
para promover la delación en el proceso penal. En el terreno judicial, se mantiene así la idea inquisitorial de que "en el Santo Oficio no se suelen admitir denunciaciones fundadas en interés y en prometidos de dinero, tanto por la santidad de la Inquisición y su pureza, como porque semejantes indicios están llenos de sospechas de falsedad y no merecen crédito ninguno conforme a las leyes" ${ }^{30}$, tal y como señalaba el Inquisidor General Sandoval y Rojas al Duque de Lerma, en una carta escrita en el año 1616. Y sin embargo, en el terreno administrativo y financiero, subsisten ciertos ejemplos de recompensas económicas a favor de aquel que denuncie la existencia de bienes y derechos de titularidad pública en manos privadas (también aplicable a quien informe de una herencia intestada a favor del Estado o CC.AA.), así como también se prevén exenciones o rebajas de las sanciones económicas a quien, habiendo participado en un cártel, denuncie en primer lugar su existencia y aporte pruebas sustantivas para su investigación a la Comisión Nacional de los Mercados y la Competencia (los llamados "Programas de Clemencia" incorporados en los artículos 65 y 66 de Ley 15/2007 de Defensa de la Competencia), así como también se prevé la exención de responsabilidad tributaria a quien denuncie haber efectuado un pago en efectivo incumpliendo la limitación legal tributaria cuando el denunciante informe a la Agencia Estatal de Administración Tributaria de la operación realizada, su importe y la identidad de la otra parte interviniente.

\subsubsection{LAS RECOMPENSAS PENALES: EXCUSAS ABSOLUTORIAS Y ATENUANTES}

Sin duda, el sector del ordenamiento jurídico con mayores ejemplos de incentivos a la delación es el Derecho Penal, o si se prefiere, el Derecho Penal Premial. A lo largo del Código Penal se aprecian diversos ejemplos en los que se premia a aquél que denuncia ante las autoridades determinadas conductas delictivas en las que hubiese participado, y la respuesta a dicha delación es su exención de responsabilidad penal. Como ejemplos, véanse la posibilidad establecida en el art.

${ }^{30}$ GALVÁN RODRÍGUEZ, E., El Inquisidor General, Dykinson, S.L., Madrid, 2010, p. 260, citado por GONZÁLEZ-CUÉLLAR SERRANO, N., Ecos de Inquisición, Ediciones Jurídicas Castillo de Luna, Madrid, 2014, p. 234 y ss. 
171.3 CP de no acusar a la persona que hubiera cometido un delito leve y denunciara a quien le está amenazando con revelar tales hechos si no efectúa una determinada acción -generalmente, la entrega de una prestación económica ${ }^{31}$; las distintas exenciones y atenuantes en materia de delitos contra la Hacienda Pública y contra la Seguridad Social que prevén los arts. 307.3 y 307.5, 307 ter 3, 308.5 y 308.7 en los casos de que el acusado regularice su situación fiscal o ante la Seguridad Social, y reintegre o devuelva las prestaciones y subvenciones indebidamente percibidas; la exención penal del art. 426 CP para el que, habiendo entregado ocasionalmente dinero o cualquier otra dádiva a un funcionario público solicitada por éste, denunciare el hecho a las autoridades antes de la apertura del procedimiento, y en un determinado periodo de tiempo; la exención del art. 462 CP para quien se retracta en tiempo y forma de haber prestado falso testimonio en un proceso penal y manifieste la verdad para que surta efecto antes de que se dicte sentencia en dicho proceso; o la exención del art. $480 \mathrm{CP}$ para quien evite un delito de rebelión si informase a tiempo de poder evitar sus consecuencias.

Junto con la regulación de dichas excusas absolutorias, también son conocidos los tipos penales atenuados con "premio a la delación ${ }^{32}$ " referidos a los delitos de organizaciones criminales, terrorismo y tráfico de drogas, con respecto a los cuales se prevén incentivos penitenciarios (art. $90.8 \mathrm{CP}$ ) y tipos penales privilegiados (v. gr., los arts. 376, 570 quater $4^{\circ}$ y 579 bis $3^{\circ} \mathrm{CP}$ ) con el objetivo de fomentar la desvinculación del arrepentido con la organización criminal mediante la rebaja de la pena en uno o dos grados si colabora y ayuda a la obtención de pruebas decisivas para la identificación o captura de otros responsa-

31 Lo califican como cláusula procesal incluida en el Código Penal FERNÁNDEZ RODRÍGUEZ, M. D., El chantaje, ed. PPU, Barcelona, 1995, pág. 125; RODRÍGUEZ DEVESA, J.M. y SERRANO GÓMEZ, A., "Delitos contra la libertad y seguridad", en Derecho Penal español. Parte especial, ed. Dykinson, Madrid, 1995, pág. 304; BARQUíN SANZ, J. "Notas acerca del chantaje y de la cláusula de oportunidad en su persecución”, Revista Electrónica de Ciencia Penal y Criminología (RECPC), vol. 4 (2002), edición online disponible en: http://criminet.ugr.es/recpc/recpc_04-01.html.

32 DIAZ-MAROTO VILLAREJO, J., "Algunos aspectos jurídico-penales y procesales de la figura del «arrepentido»", Diario La Ley, núm. 4132, de 27 de septiembre de 1996. 
bles o para impedir la actuación o el desarrollo de las organizaciones o asociaciones a las que haya pertenecido. Este premio penológico a la delación ha estado presente a lo largo de las diversas Leyes Penales que nos encontramos en la historia española, en donde existen innumerables ejemplos en los que el suministro de información a las autoridades sobre los demás miembros de la sociedad secreta, logia, banda armada, cuadrilla de bandidos, etc., era recompensada, bien con la atenuación, bien con la remisión total de la pena ${ }^{33}$. Y lo cierto es que siempre ha sido una recompensa rechazada doctrinalmente al considerarse que "un tema cuya inmoralidad intrínseca, consistente en el fomento de la delación, no puede ni siquiera justificarse en el éxito de la investigación. El interés público no puede servir de cobertura para albergar cualquier actividad que repugna a la conciencia ${ }^{34 "}$.

Pues bien, junto con esos tipos atenuados expresamente previstos para el arrepentido en los delitos de organizaciones criminales, terrorismo y tráfico de drogas, el Tribunal Supremo español ha expandido a cualquier delincuente arrepentido que colabore con la Justicia a través de la facilitación de información a las autoridades, el incentivo previsto en la atenuante analógica del apartado $7^{\circ}$ del art. $21 \mathrm{CP}$, en relación con la de confesión del apartado $4^{\circ}$, por considerar que deben fomentarse, bajo fundamentos de política criminal referidos a la utilidad de las investigaciones, aquellas actitudes de colaboración útil en la investigación de los hechos en función de su utilidad para facilitar la investigación, ayudar al esclarecimiento de los hechos investigados y, en suma, ahorrar costes a las Administración de Justicia, pues el auxilio ofrecido a la Justicia ahorraría también la ejecución de la responsabilidad civil ${ }^{35}$, más allá de los supuestos expresamente previstos en materia de terrorismo y tráfico de drogas. Hace ya tiempo que el Tribunal Supremo modificó

33 Como estudio específico relativo a la dimensión penal de la colaboración del terrorista arrepentido, vid. CUERDA-ARNAU, M. L., Atenuación y remisión de la pena en los delitos de terrorismo, ed. Centro de Publicaciones del Ministerio de Justicia, Madrid, 1995, p. 28 y ss.

34 Por resumir, citamos la opinión del Informe de la Asociación Profesional de la Magistratura al Anteproyecto de Código Penal de 1992, publicado en Cuadernos de Política Criminal, no 47, 1992, p. 309 y ss.

35 Vid. SSTS, Sala de lo Penal, de 21 de octubre de 2003 y de 7 de febrero de 2005. 
puso de manifiesto la necesidad de superar la concepción de la atenuación basada en motivaciones pietistas o de arrepentimiento y atender a razones de política criminal, pues la confesión ahorra esfuerzos de investigación y facilita la instrucción de la causa criminal ${ }^{36}$. En este sentido, son muy ejemplificativas las afirmaciones de la STS 516/2013, de 20 de junio de 2013: "la razón de la misma [la rebaja de la pena por colaboración activa] no estriba en el factor subjetivo de pesar y contrición, sino en el dato objetivo de la realización de actos de colaboración a la investigación del delito. En las atenuantes 'ex post facto' el fundamento de la atenuación se encuadra básicamente en consideraciones de política criminal, orientadas a impulsar la colaboración con la justicia en el concreto supuesto del art. 21.4 CP, pero en todo caso debe seguir exigiéndose una cooperación eficaz, seria y relevante aportando a la investigación datos especialmente significativos para esclarecer la intervención de otros individuos en los hechos enjuiciados (...). Esta atenuante analógica se fundamenta en una cooperación del acusado con la autoridad judicial tras la detención de aquél en orden al más completo esclarecimiento de los hechos investigados, reveladora de una voluntad de coadyuvar a los fines del ordenamiento jurídico que contrarresten la anterior voluntad antijurídica mostrada al cometer la infracción”.

\subsubsection{LAS RECOMPENSAS PROCESALES}

La aplicación al delincuente arrepentido de las excusas absolutorias o tipos atenuados expresamente previstos en ese Derecho Penal Premial, incluida la atenuante analógica de colaboración con la Justicia, requiere en todo caso de la celebración de un proceso penal y del dictado de una sentencia (aunque sea de conformidad). Sin embargo, y como quiera que la colaboración del acusado interesa fomentarla desde los inicios de la investigación judicial o policial como acicate para la obtención de nuevas pruebas, comienza a percibirse que el mejor premio a conceder al delator no es únicamente de tipo sustantivo (la atenuación de la pena, o bien su exención de responsabilidad penal) sino que también es de índole

36 Vid. SSTS, Sala de lo Penal, de 23 de junio de 2004, 5 de octubre de 2010 y 18 de febrero de 2014. 
procesal, y se traduce, de una parte, en la adopción de medidas procesales de protección durante o después del proceso penal en el que el delator testifica incriminando a terceros, y de otra parte, en la clara rebaja de la acusación planteada por el acusador oficial (Ministerio Fiscal), así como en el levantamiento o minoración de las medidas cautelares adoptadas contra el coimputado que colabora eficazmente con la Justicia.

Estos incentivos procesales al delator durante la fase de investigación criminal dan lugar a que se avance desde lo puramente penal a lo procesal, pues dicha colaboración persigue mejorar la eficacia estatal en la adquisición de pruebas procesales ${ }^{37}$, y todo ello sin necesidad de una reforma legal explícita que incorpore concretos tipos atenuados o eximentes penales. Basta con una interpretación "dulcificada" de los requisitos y presupuestos procesales para el ejercicio de la acusación o para la adopción o modificación de las medidas de investigación y medidas cautelares que puedan adoptarse contra el investigado en función de su grado de colaboración. Por ello nos encontramos ante una evolución jurisprudencial sin reforma legal que lo sustente, en donde los tribunales han potenciado esta visión pragmática del proceso para obtener información por parte del "colaborador" (obsérvese como el uso de expresiones más neutras como "colaborador con la Justicia” o "informante" persigue también ese objetivo de minorar la visión despectiva de términos tales como chivato, soplón o traidor) a cambio de beneficios procesales, entre los que podemos destacar dos ejemplos reales concretos:

En primer lugar, el levantamiento de la medida cautelar de prisión provisional. En el famoso "caso Malaya" (una macrocausa de corrupción y blanqueo de capitales) el Juez Instructor de la causa declaró en uno de sus Autos judiciales sobre la puesta en libertad de un investigado que "No olvidemos que la colaboración con la justicia es una actitud procesal a la que la Ley atribuye beneficios de esta índole ${ }^{38 ”}$. Y en

37 BENÍTEZ ORTÚZAR I. F., El colaborador con la Justicia. Aspectos sustantivos procesales y penitenciarios derivados de la conducta del «arrepentido», Madrid, Dykinson, 2004, p. 35.

38 Citado por GONZÁLEZ-CUÉLLAR SERRANO, N., "Halcones y Palomas: la persecución penal de la corrupción y de la delincuencia económica”, en VV.AA., Halcones y Palomas: corrupción y delincuencia económica, ediciones jurídicas Castillo de Luna, Madrid, 2015, p. 537. 
la llamada "operación Púnica" también el Juez Central de Instrucción $\mathrm{n}^{0} 6$ de la Audiencia Nacional acordó reformar la prisión provisional del acusado (de prisión provisional incondicional se pasó a una libertad bajo fianza de 100.000 euros) ante "la colaboración eficaz y de forma positiva con la investigación, admitiendo los hechos, aportando evidencias documentales incriminatorias y auxiliando al juzgado en la recuperación de activos de origen delictivo, lo cual redunda en una reducción de los riesgos de alteración y destrucción de pruebas”.

En segundo lugar, la suavización de las medidas cautelares adoptadas durante la fase instructora contra el acusado-delator que se presta a colaborar con las autoridades también se ha traducido, en la práctica, en la denegación de la extradición pasiva de aquel sujeto que, siendo reclamada su entrega a las autoridades extranjeras en virtud de una Orden Internacional de Detención con fines de extradición, llevara a cabo una importante labor colaboradora con las autoridades españolas en la lucha contra el crimen organizado, tal y como aconteció con el señor Hervé Falciani y la denegación de su extradición a Suiza por inexistencia de doble incriminación ${ }^{39}$. Aunque el thema decidendi de la decisión de la Sala de lo Penal de la Audiencia Nacional para denegar la extradición fuera la falta de concurrencia de la doble incriminación de las conductas penales atribuidas al Sr. Falciani (la sustracción de información, violación del secreto comercial, violación de secreto bancario y delito de espionaje económico), interesa destacar como la Audiencia Nacional valoró expresamente la actitud colaboradora del sr. Falciani con las autoridades españolas a la hora de examinar la posible responsabilidad penal de aquel por un posible delito de revelación de secretos, infidelidad en la custodia de documentos, etc., así como la inexistencia de móviles espurios o bastardos en dicha actitud colaboracionista (la entrega de información a cambio de dinero), rechazando que tales extremos hayan quedado acreditados en la causa. Es decir, la existencia de tales motivos sería también valorable a la hora de determinar si ha existido o no colaboración con la justicia merecedora de un trato procesal más favorable.

39 Véase el Auto núm. 19/2013, de 8 de mayo, de la Sala de lo Penal (secc. 2a) de la Audiencia Nacional. 
Por último, y específicamente referido al ámbito de la responsabilidad penal de las personas jurídicas, también se ha defendido que los estímulos procesales serían más eficaces que los estímulos penales, sobre todo cuando se pretende la colaboración efectiva por parte de una persona jurídica, pues su sometimiento a un proceso penal es ya de por sí un hecho negativo que, más allá de costes reputacionales, puede llegar a afectar al desarrollo de su actividad (precinto y clausura de locales, embargo de cuentas bancarias, interrogatorio de directivos y adopción de prisión provisional en su contra, intervención judicial de la empresa, etc.) e implicar la pérdida de negocios, de modo que se ha reclamado que la debida colaboración eficaz de la persona jurídica encausada durante la fase de investigación sea valorada positivamente a la hora de acordar medidas cautelares y diligencias de investigación ${ }^{40}$. En este sentido, la Circular 1/2016 de la Fiscalía General del Estado señala expresamente que “(...) la colaboración activa con la investigación o la aportación al procedimiento de una investigación interna, sin perjuicio de su consideración como atenuantes, revelan indiciariamente el nivel de compromiso ético de la sociedad y pueden permitir llegar a la exención de la pena. Operarán en sentido contrario el retraso en la denuncia de la conducta delictiva o su ocultación y la actitud obstructiva o no colaboradora con la justicia”, de modo que ese argumento también servirá a la Fiscalía, más allá de solicitar la aplicación o no de la atenuante, para solicitar la no adopción de medidas cautelares contra la persona jurídica objeto de investigación.

\subsection{LA RETIRADA O SUSPENSIÓN DE LA ACUSACIÓN POR COLABORACIÓN CON LA JUSTICIA}

La actual configuración del sistema acusatorio penal en España impide la retirada de la acusación o la suspensión de la misma ante la constatación de un hecho delictivo, de modo que al acusador público le está vedado solicitar el sobreseimiento de la causa. Sin embargo, todo a punta a que el futuro proceso penal español incorporará como supuesto

40 NIETO MARTÍN, A., en VV.AA., Manual de cumplimiento penal de la empresa, ed. Tirant lo Blanch, Valencia, 2015, pp. 93 y 260. 
de suspensión o retirada de la acusación, la colaboración eficaz con las autoridades, y ello a través de una potenciación del principio de oportunidad basado en motivos de interés público.

Lo llamativo de estas propuestas "lege ferenda" es que dicha suerte de inmunidad procesal para el delator que se preste a colaborar con la Justicia no sería novedosa en España, pues ya en la Pragmática de Felipe IV de 6 de julio de $1663^{41}$ se preveía que "si el que entregare alguno de los dichos bandidos no hubiere cometido delito, queremos, que si el dicho bandido fuera cabeza de cuadrilla o tropa se le conceda indulto para dos delinqüentes y si no fuere cabeza de cuadrilla se le conceda el indulto para un delinqüente, como no sea de los salteadores bandidos, ni haya cometido alguno de los tres crímenes exceptuados (herejía, de lesa Majestad y de moneda falsa)". Y hasta la reforma del Código Penal de 1988, las diversas Leyes Penales españolas preveían la remisión total de la pena como premio al suministro de información a las autoridades sobre los demás miembros de la sociedad secreta, logia, banda armada, cuadrilla de bandidos, etc ${ }^{42}$. De modo que lo que ahora se discute doctrinalmente en España sería, por tanto, la posibilidad o no de reintroducir en nuestra regulación la figura conocida como el "Testigo de la Corona" utilizado en aquellos ordenamientos en los que el ejercicio de la acción penal se encuentra atribuida exclusivamente a un órgano estatal (Ministerio Público) y rige el principio de oportunidad.

Este premio procesal al chivato arrepentido se viene usando en el proceso penal de tipo anglosajón ya desde el siglo XIV - a través del mecanismo que se denominaba approvement o turning King's evidence y que establecía la posibilidad de acordar el archivo de la causa para aquel acusado que confesare los hechos e inculpara, aportando suficientes pruebas, al resto de partícipes, siempre que aquellos fueran finalmente condenados $^{43}$. Además de seguir vigente en muchos países del Common Law, también se han articulado distintos modelos de inmunidad procesal actualmente en vigor en diversos países de Latinoamérica, en don-

41 Citada por CUERDA-ARNAU, M. L., Atenuación y remisión de la pena..., op. cit., p. 32.

42 CUERDA-ARNAU, M. L., ídem, p. 28 y ss.

43 Vid. MUSSON, A. J., 'Turning King's Evidence: The Prosecution of Crime in Late Medieval England', Oxford Journal of Legal Studies, Vol. 19, 1999, pp. 467-480. 
de se permite acordar la inmunidad procesal para aquel miembro de la delincuencia organizada que preste ayuda eficaz para la investigación y persecución de otros miembros de la misma, cuando no exista averiguación previa en su contra (México y Perú); la posibilidad de suspender, interrumpir o renunciar a la persecución penal, en aplicación del principio de oportunidad, cuando el imputado colabore eficazmente para evitar que continúe el delito o se realicen otros, o aporte información esencial para la desarticulación de bandas de delincuencia organizada, o cuando el imputado sirva como testigo principal de cargo contra los demás intervinientes (Colombia); o las diversas medidas premiales de reducción y de exención de la responsabilidad penal para quien colabore eficazmente con la Justicia (Brasil).

La posibilidad de llegar a permitir en España la retirada de la acusación contra el colaborador con la Justicia ha sido fuertemente criticada por algún sector doctrinal, por considerar que la exención total de la pena a favor del delator colaborador con la Justicia sería casi equiparable a un indulto judicial ${ }^{44}$, y supondría un beneficio desmedido a favor del inculpado pues significaría el perdón del inculpado por los hechos delictivos por él cometidos ${ }^{45}$. Para este sector crítico, significaría dar por buena la premisa de que el Estado es incapaz de desempeñar una lucha eficaz contra la delincuencia organizada, de modo que la generalización de medidas previstas en su día con carácter excepcional en la lucha antiterrorista podrían generar intromisiones policiales "intolerables" en el proceso penal ${ }^{46}$, porque esos incentivos deberían tener un ámbito temporal y excepcional, y no, como parece, con vocación de permanencia, pues sería más aconsejable, en tales casos, la vía del indulto ${ }^{47}$.

Otros han llegado más lejos, al estimar que la introducción de supuestos de acusación "negociada” en el proceso penal podría dar lugar

44 BENÍTEZ ORTÚZAR, I. F., El colaborador con la justicia..., op. cit., p. 192.

45 SOTO RODRÍGUEZ, M. L., "El arrepentimiento en el delito de tráfico de drogas. Artículo 376 del Código Penal”, Diario La Ley, núm. 7856, de 11 de mayo de 2012.

46 SERRANO-PIEDECASAS FERNÁNDEZ, J. R., Emergencia y crisis del Estado social: análisis de la excepcionalidad penal y motivos de su perpetuación, ed. PPU, Barcelona, 1988, p. 208.

47 DIAZ-MAROTO VILLAREJO, J., “Algunos aspectos...”, op. cit., p. 1465. 
a que los interrogatorios durante la fase de investigación se conviertan en un método inquisitorial de obtención de pruebas $^{48}$ y favorecer conductas del acusador en donde su primer escrito de acusación ya no fuera el resultado de la precisa valoración de los hechos y del resultado de la actividad probatoria a desarrollar en el plenario, sino más bien "una mera declaración de intenciones en la que asistiremos a un artificioso agravamiento de las consecuencias penales, más allá de lo que el propio acusador considera una solución justa”, que incluso "podría dar pie a que intimidara al acusado con la posibilidad de ampliar la acusación a terceras personas vinculadas sentimentalmente con él o con posicionarse en contra de sus intereses en la obtención de determinados beneficios" si el acusado no se aviene a colaborar en el descubrimiento de los hechos, de modo que el Fiscal podría convertirse así en el dominador del proceso penal y, en consecuencia, de la eventual aplicación del ius puniendi del Estado, actuando supra voluntas legislatorem, como si de un legislador negativo se tratara ${ }^{49}$.

También se ha criticado su carácter desigualitario, porque al premiar la colaboración para el descubrimiento de tramas delictivas, podrían beneficiarse de ellas en mayor medida los integrantes de los niveles superiores de la organización, que tienen mayor información que ofrecer, frente a los subordinados. Esto es, se premiaría más al que más sabe, y por tanto, al más culpable, esto es, a quien tendría que imputársele una mayor responsabilidad penal ${ }^{50}$. Quizás por ello, algunos ordenamientos jurídicos excluyen expresamente de este "perdón judicial" a los cabecillas o líderes de las tramas criminales.

Y en último término, y quizá la crítica más importante a la introducción de supuestos de acusación "negociada” en el proceso penal, sea el temor a volver a tiempos en los que los interrogatorios durante la fase de investigación se conviertan en un método inquisitorial de obtención de pruebas ${ }^{51}$ y a los posibles abusos que dicho amplio margen de

48 LAMARCA PÉREZ, C.: Tratamiento jurídico del terrorismo. Ministerio de Justicia, Madrid, 1985, p. 348.

49 CABEZUDO RODRÍGUEZ, N., "Sobre la conveniencia de atribuir la instrucción penal al ministerio fiscal”, Revista Jurídica de Castilla y León, 2008, núm. 14, p. 211.

50 SOTO RODRÍGUEZ, M., "El arrepentimiento...”, op. Cit.

51 LAMARCA PÉREZ, C.: Tratamiento jurídico..., op. cit., p. 348. 
discrecionalidad a conceder al Ministerio Fiscal podrían producirse en la práctica. Esas facultades de archivo por motivos de oportunidad podría dañar la igualdad de las partes, en cuanto dicha negociación puede conducir al imputado a una "mala" suerte de coacción, pues mientras para el Ministerio Fiscal la negociación es un caso más, para el acusado es el momento en que se decide su futuro, de modo que no es posible hablar aquí de la igualdad de las partes contratantes en una negociación contractual privada tradicional, sino que al hablar de negociación procesal es hacer uso de un eufemismo tras el cual se halla, en la mayoría de las veces, un "lo tomas o mayor pena"

A pesar de tales críticas, las reformas legislativas aprobadas, así como las proyectadas en España, ahondan en ese camino hacia una mayor potenciación de las facultades del acusador público para negociar la pena solicitada, suspender la acusación, o directamente proponer el archivo de la causa por motivos de oportunidad. Como muestra, la reforma de la Ley de Enjuiciamiento Criminal en virtud de la Ley Orgánica $1 / 2015$, de 30 de marzo, por la que se modifica el Código Penal, ha venido fijar aún con mayor claridad esa política criminal del legislador referida a introducir criterios de oportunidad en la persecución y enjuiciamiento de los delitos leves (la denominada delincuencia de bagatela, o en palabras del legislador, "conductas de escasísima gravedad ${ }^{53}$ ") como instrumento para agilizar la Justicia Penal basado en criterios tan utilitaristas o pragmáticos como la propia economicidad del proceso, esto es, cuando la escasa gravedad de la acción o la ausencia de un verdadero interés público en su persecución no justifiquen la apertura de un proceso penal.

En el mismo sentido, las propuestas legislativas de reforma de la LECrim tanto en 2011 como en 2013 apostaban por incluir manifestaciones del principio de oportunidad procesal para incentivar la colaboración de determinados sujetos en la investigación y desbaratamiento de las redes de criminalidad organizada (es decir, no sólo frente a los delitos

52 SANTANA VEGA, D. M., "Principio de oportunidad y sistema penal", Anuario de derecho penal y ciencias penales, Tomo 47, 1994, p. 125.

53 Vid. la Exposición de Motivos de la Ley Orgánica 1/2015, de 30 de marzo, por la que se modifica la Ley Orgánica 10/1995, de 23 de noviembre, del Código Penal. (BOE núm.77, de 31 de marzo de 2015). 
bagatela). En concreto, la propuesta de reforma de la LECrim presentada en 2011 ya incorporaba determinadas modalidades de oportunidad, entre las cuales se preveía el archivo del procedimiento "por colaboración activa contra una organización criminal" (art. 153), aunque sólo para delitos cometidos en el seno de una organización criminal y castigados con penas de hasta seis años de prisión, y siempre que el colaborador cumpliera una serie de requisitos legalmente previstos. Y la propuesta de Código Procesal Penal de 2013 ampliaba tales límites, al instaurar con carácter general en nuestro ordenamiento el principio de oportunidad, en virtud de criterios legalmente previstos, entre los que se incluía el supuesto en que el autor o participe en el hecho punible perteneciera a una organización o grupo criminal y fuera el primero de los responsables en confesar el delito, y siempre que prestase una plena colaboración con la Administración de Justicia y la misma fuera considerada de suficiente relevancia a criterio del Fiscal General del Estado (art. 91.4 CPP), de un modo similar a lo previsto en el § 153e StPO en los casos de arrepentimiento activo y colaboración del autor el hecho punible ${ }^{54}$.

Como vemos, esa posibilidad de no acusar a quien sea el primero en confesar el delito y colaborar eficazmente con las autoridades no sería sino la introducción en el Proceso Penal de los "Programas de clemencia" ya incorporados en el ámbito administrativo sancionador del Derecho de la Competencia desde 2007, cuya eficacia depende, en gran medida, de los incentivos que tengan los posibles solicitantes para presentar solicitudes de exención y/o reducción de la posible multa ${ }^{55}$. Y a ello debemos añadir la corriente legislativa actual a nivel internacional que aboga, no sólo por la incorporación de medidas de protección a los colaboradores con la justicia que tienen además la condición de imputados en el proce-

54 A favor del sobreseimiento de la causa por motivos de oportunidad basados en la colaboración eficaz del delator, GIMENO SENDRA ("Corrupción y propuestas de reforma”, Diario La Ley, n 7990, de 26 de diciembre de 2012 y “El principio de oportunidad y el Ministerio Fiscal”, Diario La Ley no 8746, de 21 de abril de 2016). En contra, vid. CUADRADO SALINAS, C., "La suspensión condicional de la acción penal: luces y sombras del borrador de código procesal penal", Revista General de Derecho Procesal, n 35, 2015.

55 GUZMÁN ZAPATER, C., "el 'programa de clemencia' en el sistema español de defensa de la competencia: una visión práctica”, Working Paper IE Law School, AJ8-188, 31-07-2012. 
so, sino también a través de la regulación de la atenuación de la pena en casos de cooperación sustancial, e incluso a la inmunidad judicial como fórmula válida para promocionar la cooperación con la Justicia de personas que participen o hayan participado en la comisión de delitos, tal y como se prevé en el art. 26.3 de la Convención de las Naciones Unidas contra la delincuencia organizada transnacional o en los arts. 33 y 37 de la Convención de las Naciones Unidas contra la Corrupción.

\section{Conclusiones}

La posibilidad de establecer importantes beneficios a los que pueda acceder el miembro de la trama corrupta que se preste para colaborar con la autoridad en la persecución de otros miembros de la organización significa conceder al Ministerio Público - como transmisor en el proceso penal de la política criminal que quiera fijar el gobierno - un importante margen de discrecionalidad para renunciar a la persecución de dichas personas por ciertos delitos, o someter su decisión de sobreseimiento al cumplimiento de determinadas condiciones, como instrumento de política criminal bajo la pragmática decisión de obtener información potencialmente relevante para identificar a otros autores del delito y, particularmente, para desintegrar las organizaciones criminales a las que el investigado arrepentido hubiere pertenecido o con las que hubiere colaborado.

Pero también hay que reconocer que esta solución pragmática, que puede ser abordada desde el plano material penal (reducción o completa exención de responsabilidad penal) o desde el plano procesal (inmunidad procesal del delincuente colaborador con la Justicia o suspensión temporal y condicionada de la acusación en su contra), chirría con los tradicionales fines de la pena y podría no ser comprendida por la Sociedad, que vería como el sujeto infractor no sólo no es severamente castigado por sus delitos, sino incluso recompensado por su actuación colaboradora con las autoridades estatales.

No obstante, y frente a las citadas críticas en contra de la incorporación de estas teorías utilitaristas al proceso penal español, es preciso recordar que actualmente, y sin necesidad de introducir reforma alguna en nuestro sistema, la vigencia de la doctrina según la cual el juicio 
oral por determinados delitos sólo puede ser instado por la Fiscalía, y en su caso, por la acusación particular si la hubiere (las célebres doctrina Botín y doctrina Atutxa de nuestro Tribunal Supremo), unida a los amplios márgenes con los que el Ministerio Público puede pactar una sentencia de conformidad con el acusado, ya permite al Estado utilizar tales posibilidades como instrumentos para obtener una mayor colaboración del acusado a cambio de esa "dulcificación" de la pena a imponer.

Es evidente que estas opciones premiales a favor de quien aporte información durante el proceso penal, bien mediante la aprobación de adecuadas medidas de protección, pero sobre todo cuando se trata de importantes beneficios penales y procesales para el delincuente arrepentido, plantean también dilemas de tipo moral, pues ¿̇hasta qué punto debemos recompensar con una zanahoria a quien ha cometido un delito?

Pero ante dicha postura cabe argumentar igualmente que, si se estima que la sanción a una conducta negativa (la comisión del delito) puede ser penalmente minorada si el infractor realiza una conducta positiva y en sentido contrario (v. gr., la reparación del daño o la confesión de los hechos), de igual modo cabría admitirse que dicha conducta negativa puede ser reconducida a través de instrumentos procesales (por ej., mediante la decisión de no acusar por determinados hechos delictivos leves, la retirada de la acusación cuando exista una colaboración eficaz, o la suspensión de la misma condicionada a determinados cumplimientos), cuando el acusado lleve a cabo una determinada conducta de signo positivo que redunde en un beneficio, no sólo para la víctima, sino también para el propio Estado. Si la reparación del daño tiene como beneficiario directo a la víctima de los hechos, la colaboración en la desarticulación de la trama organizada y la captura de los responsables tiene como beneficiario a la propia Administración de Justicia, que tendrá que dedicar menos recursos a la investigación y persecución de esas conductas y podrá utilizar los escasos y preciados medios materiales y personales con los que cuenta para otras investigaciones aún por descubrir.

Es más, consideramos que los incentivos procesales dirigidos para promocionar dicha colaboración pueden ser más efectivos que los beneficios penales. Primero, porque su campo de acción es mucho más amplio, tanto desde una perspectiva objetiva como subjetiva. Desde el plano objetivo, porque más allá de su expresa regulación penal a través 
de concretos tipos atenuados como sucede en los casos de terrorismo y tráfico de drogas, se podrá emplear para combatir aquella criminalidad caracterizada por su opacidad y dificultad para acceder a la información (crimen organizado, corrupción política, fraudes societarios y delincuencia económico-empresarial, etc.). Y desde el plano subjetivo, al dirigirse no sólo a los partícipes de la trama delictiva -los denominados arrepentidos-, sino a cualquier ciudadano, empleado, funcionario, etc., con información muy atractiva para las autoridades -los que, bajo la genérica denominación de soplones o delatores, en el proceso penal reciben diversos estatus o calificativos como "denunciantes anónimos", “confidentes", "testigos protegidos", etc.-. Y segundo, porque la promoción de la delación a través de la retirada, archivo, suspensión o transacción con la acusación penal en la propia fase de investigación permitirá, en palabras de Gimeno Sendra, la simplificación y una mejor aplicación del ius puniendi, al resultar antieconómico e ineficaz la instauración de todo un proceso penal hasta la obtención de una sentencia firme para poder beneficiar al arrepentido ${ }^{56}$.

\section{Bibliografía}

ARIAS RODRÍGUEZ, J. M., "Algunas reflexiones sobre la política anticorrupción en la Unión Europea”, Diario La Ley, núm. 7989, de 21 de diciembre de 2012.

BARQUÍN SANZ, J. "Notas acerca del chantaje y de la cláusula de oportunidad en su persecución”, Revista Electrónica de Ciencia Penal y Criminología (RECPC), vol. 4 (2002), edición online disponible en: http://criminet.ugr.es/ recpc/recpc_04-01.html.

BENÍTEZ ORTÚZAR I. F., El colaborador con la Justicia. Aspectos sustantivos procesales y penitenciarios derivados de la conducta del «arrepentido», Madrid, Dykinson, 2004.

CABEZUDO RODRÍGUEZ, N., "Sobre la conveniencia de atribuir la instrucción penal al ministerio fiscal”, Revista Jurídica de Castilla y León, 2008, núm. 14.

CASTRO CAMERO, R., El crimen maiestatis a la luz del senatus consultum de Cn. Pisone Patre, ed. Universidad de Sevilla, Sevilla, 2001.

56 GIMENO SENDRA, V., "El principio de oportunidad y el Ministerio Fiscal", Diario La Ley $\mathrm{n}^{\circ}$ 8746, de 21 de abril de 2016. 
CATTAN ATALA, A., LOYOLA NOVOA, H., "Los delatores", Revista Chilena de Historia del Derecho, núm. 14 (1991).

CUADRADO SALINAS, C., "La suspensión condicional de la acción penal: luces y sombras del borrador de código procesal penal”, Revista General de Derecho Procesal, $\mathrm{n}^{\circ}$ 35, 2015.

CUBILLO LÓPEZ, I. J., La protección de testigos en el proceso penal, ed. Thomson Reuters, Madrid, 2009.

CUERDA-ARNAU, M. L., Atenuación y remisión de la pena en los delitos de terrorismo, ed. Centro de Publicaciones del Ministerio de Justicia, Madrid, 1995.

DE MOscoso Y SANDOVAL, B., Constituciones Sinodales del obispado de Jaén. Sínodo diocesana que se celebró en la ciudad de Jaén en 1624. Segunda impresión, Jaén, 1787.

DIAZ-MAROTO VILLAREJO, J., "Algunos aspectos jurídico-penales y procesales de la figura del «arrepentido»”, Diario La Ley, núm. 4132, de 27 de septiembre de 1996.

FERNÁNDEZ RODRÍGUEZ, M. D., El chantaje, ed. PPU, Barcelona, 1995.

GARCÍA CAMIÑAS, J., Delator, una aproximación al estudio del delator en las fuentes romanas, Santiago de Compostela, 1983. Vid. también Ídem, "Deferre ad aerarium", AFDUDC, núm. 10, 2006.

GIMENO SENDRA, V., "El principio de oportunidad y el Ministerio Fiscal", Diario La Ley $\mathrm{n}^{\circ}$ 8746, de 21 de abril de 2016.

GIMENO SENDRA, V., "Corrupción y propuestas de reforma”, Diario La Ley, n ${ }^{\circ}$ 7990, de 26 de diciembre de 2012.

GONZÁLEZ-CUÉLLAR SERRANO, N., Ecos de Inquisición, Ediciones Jurídicas Castillo de Luna, Madrid, 2014.

GONZÁLEZ-CUÉLLAR SERRANO, N., "Halcones y Palomas: la persecución penal de la corrupción y de la delincuencia económica”, en VV.AA., Halcones y Palomas: corrupción y delincuencia económica, ediciones jurídicas Castillo de Luna, Madrid, 2015.

GUERRERO, M., "El praemium civitatis en la lex Acilia repetundarum: ¿incentivo para reprimir el abuso de poder?", Rivista Internazionale di Science Giuridiche e Tradizione Romana, nr. 12, 2014. Versión online disponible en la página web: http://www.dirittoestoria.it/12/tradizione-romana/Guerrero-Praemiumcivitatis-lex-Acilia.htm. 
GUZMÁN ZAPATER, C., "el 'programa de clemencia' en el sistema español de defensa de la competencia: una visión práctica”, Working Paper IE Law School, AJ8-188, 31-07-2012.

LAMARCA PÉREZ, C.: Tratamiento jurídico del terrorismo. Ministerio de Justicia, Madrid, 1985.

MUSSON, A. J., 'Turning King's Evidence: The Prosecution of Crime in Late Medieval England', Oxford Journal of Legal Studies, Vol. 19, 1999.

NIETO MARTÍN, A., en VV.AA., Manual de cumplimiento penal de la empresa, ed. Tirant lo Blanch, Valencia, 2015.

ORTIZ PRADILLO, J. C., "El difícil encaje del delator en el proceso penal" en el Diario La Ley, núm. 5860, de 12 de junio de 2015.

RODRÍGUEZ DEVESA, J.M. y SERRANO GÓMEZ, A., "Delitos contra la libertad y seguridad", en Derecho Penal español. Parte especial, ed. Dykinson, Madrid, 1995.

RUBIO EIRE, J. V., "La posible inviabilidad de una denuncia anónima o fundada en fuentes no verificables como elemento precursor de una instrucción penal". Documento online disponible en la página web:http://www.elderecho.com/ penal/inviabilidad-verificables-elemento-precursor-instruccion_11_560680001. html. Fecha de consulta: 12 de mayo de 2015.

RUIZ VADILLO, E., "La reforma penal y la delincuencia económica. Especial referencia a la protección del consumidor”, Eguzkilore, núm. Extra 1999.

SÁNCHEZ GARCÍA DE PAZ, I., "El coimputado que colabora con la Justicia penal (con atención a las Reformas introducidas en la Regulación españolas por las leyes 7 y 15/2003)", Revista electrónica de Ciencias penales, núm. 7, 2005 (versión online disponible en: http://criminet.ugr.es/recpc/).

SANTANA VEGA, D. M., "Principio de oportunidad y sistema penal”, Anuario de derecho penal y ciencias penales, Tomo 47, 1994.

SERRANO-PIEDECASAS FERNÁNDEZ, J. R., Emergencia y crisis del Estado social: análisis de la excepcionalidad penal y motivos de su perpetuación, ed. PPU, Barcelona, 1988.

SOTO RODRÍGUEZ, M. L., "El arrepentimiento en el delito de tráfico de drogas. Artículo 376 del Código Penal”, Diario La Ley, núm. 7856, de 11 de mayo de 2012. VELASCO NÚÑEZ, E., "El confidente”, La Ley, 1993.

VV.AA., Informe de la Asociación Profesional de la Magistratura al Anteproyecto de Código Penal de 1992, publicado en Cuadernos de Política Criminal, nº 47, 1992. 


\section{DADOS DO PROCESSO EDITORIAL}

(http://www.ibraspp.com.br/revista/index.php/RBDPP/about/editorialPolicies)

- Recebido em: 20/12/2016

- Controle preliminar e verificação de plágio: 20/12/2016

- Avaliação 1: 03/01/2017

- Avaliação 2: 09/01/2017

- Avaliação 3: 14/01/2017

- Decisão editorial preliminar: $16 / 01 / 2017$

- Retorno rodada de correções 1: 20/01/2017

- Decisão editorial final: 20/01/2017

\section{Equipe editorial envolvida}

- Editor-chefe: 1 (VGV)

- Editora-associada: 1 (SRM)

- Revisores: 3

\section{COMO CITAR ESTE ARTIGO:}

ORTIZ, Juan Carlos. La delación premiada en España: instrumentos para el fomento de la colaboración con la justicia. Revista Brasileira de Direito Processual Penal, Porto Alegre, vol. 3, n. 1, p. 39-70, jan./abr. 2017. https://doi.org/10.22197/rbdpp.v3i1.38

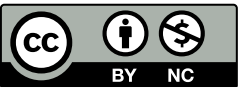

Esta obra está licenciada com uma Licença Creative Commons Atribuição-NãoComercial 4.0 Internacional. 